Article

\title{
What Attitudes Toward Refugees Do Future European Teachers Have? A Comparative Analysis between France and Spain
}

\author{
Encarnación Soriano and Verónica C. Cala * (D) \\ Department of Education, University of Almería, Cañada de San Urbano s/n. 04120 Almería, Spain; \\ esoriano@ual.es \\ * Correspondence: vcc284@ual.es; Tel.: +34950015760
}

Received: 29 April 2019; Accepted: 29 May 2019; Published: 30 May 2019

check for updates

\begin{abstract}
Background. The increase in international conflicts and humanitarian crises has led to an increase in the movement of people to Europe. The legal and moral commitments of the European Union require the incorporation and integration of such refugees. In this sense, the school and its teaching staff are a key agent in the challenge of integrating newly arrived students. This research analyses attitudes towards inclusive European citizenship, the recognition of rights, and feelings of threat and affective reactions, experienced by future teachers towards refugees in France and Spain. (2) Methods. The investigation was carried out through a cross-sectional survey. There were 851 participants of Spanish and French nationality. (3) Results. The French future teachers showed a lower perception of any threat, and a better predisposition towards the reception of refugees than their Spanish counterparts. Women are those who show a greater recognition of the rights of refugees, and a better predisposition to their integration in Europe. French women feel less of a threat than Spanish women, and are more affective towards refugees. The main predictor of inclusive European citizenship is a low perception of threat related to refugees. (4) Conclusions. Future teachers showed sensitivity towards the accommodation of refugees, but programs that prevent growing xenophobia and discredit towards the European Union are still necessary.
\end{abstract}

Keywords: attitudes toward refugees; inclusive European citizenship; teacher in training; France; Spain

\section{Introduction}

According to the United Nations High Commissioner for Refugees (UNHCR) [1], over the last four years, the largest movement of people since the Second World War has taken place. This type of phenomenon is not recent, but the impact demonstrated since 2015, as a consequence of international conflict proliferation, including the war in Syria, has led to what has been called "the European migration crisis", or "the refugee crisis in Europe". Because of this crisis, the number of forcibly displaced people was 68.5 million in 2017, of which half were minors, and 1.3 million asylum applications were requested in Europe. These movements are characterized by dangerous access routes, related to potentially traumatic migratory trips across the Mediterranean Sea. Not all of the people who get to Europe secure refugee status. According to the World Bank [2], the number of refugees was around 25 million people in 2017. Specifically, in Spain the number of refugees welcomed regularly has increased from 4003 in 1991 to 17,536 in 2017, experiencing an increase of 11,000 people over the last two years. In the case of France, in 1991 there were 174,756 and by 2017, it had gone up to 337,143, showing a progressive increase of 150,000 since 2009. According to the UNHCR ranking of the countries which take the most refugees [1,3], France is in 14th position, the second in Europe after Germany, while Spain reaches 56th position. 
Refugee status is associated with the rights of asylum and international protection, the ability to benefit from social services, and social benefits from different welcome strategies managed by Public administrations, with the main purpose of ensuring the satisfaction of basic needs under dignified conditions. Among these benefits, some remarkable ones are the educational programs which exist to stimulate their integration into host countries $[1,3,4]$. Therefore, the educational response requires an adaptation from every system which must consider specific issues related to children and young adults as refugees. One of the main obstacles which people face in such a situation is the difficulty in accessing schooling, the incomprehension of the migration process from teachers and colleagues who sometimes do not realize of the trauma caused by conflict in the child refugee, the lack of a feeling of belonging, language barriers, separation and discrimination in school environments [5], which justifies the creation of new educational strategies that respond to the global migration phenomenon [6], with a focus on improving the attitudes towards migrants and refugees, among other things [7].

The role of teachers seems to be one of the keys to the process of welcoming and integrating refugees. Studies carried out in different locations show that teachers are not still well prepared to welcome refugees, showing a lack of knowledge about their situations, and negative attitudes towards them, and acting with low empathy and intercultural competence $[8,9]$. In places with a high percentage of newly arrived refugees, such as Turkey, young and future teachers show a less caring and empathetic perspective to new refugees, with high levels of social refusal $[10,11]$. Also, in Europe, progress has been appreciated in the attitudes towards people who try to reach Europe [12-14]. A global attitudes survey [13], developed by Pew Research Centre at the end of 2017, shows that Spanish people are the most welcoming to refugees, with French people showing lower levels compared to the Spanish, while Hungarians and Bulgarians seem to be the most reticent to their incorporation.

\subsection{Reception and Integration Models in France and Spain}

Attitudes towards migration are more and more susceptible to social change, strongly related to migratory history and the national models which manage migrations and refugees in every country. These issues influence national identity, social cohesion and security policies.

The history of welcoming immigrants into France during the twentieth century is based upon multiple migratory flows, which were a consequence of the victory in the world wars, and the decolonization of its colonies (Algeria, Morocco, etc.). As a result, France is nowadays the sixth country in the world with the highest level of immigration. This culture of receiving immigrants led to a unique model of integration during the 1960s which has been denominated "the Republican French model". This model consisted of bringing about successful integration through linguistic and cultural assimilation to French republican values, and through participation in different institutions and social spaces (school, work, etc.). Although the 1980s were characterized by numerous mobilizations headed by immigrants' children showing the crisis of that model, the same approach has been used since then. In fact, after the recent debate about the use of the burkini on French coasts, a neo-republican approach has been defended again [15].

The integration model in Spain has been brought into line with those of Portugal and Greece under the name "Mediterranean immigration model", as they share many things in common. These three countries have had a very recent history of immigration, which began at the end of their dictatorships, linked to their economic growth during the 1980s, especially driven by their integration in the European Economic Community. This model groups together countries which have strategic positions over routes in the Mediterranean Sea and a lack of previous migration experience, generating large informal economies with high levels of non-regulated jobs for immigrants, making it very difficult for legal pathways to control such a situation [16]. In all of these countries, the beginning of the financial crisis resulted in a moderate emigration of people back to their countries of origin. With respect to the management of diversity, an indefinite position about integration policies has been maintained, "taking some elements from both multiculturalism and assimilationism" [17]. 


\subsection{Attitudes towards Refugees}

The construction of attitudes is not fundamentally an individual issue, as it depends on a complex combination of circumstances, predispositions, personal perceptions, values and context influences (political speech, migration policies, mass media and society). An attitude can be defined as a relatively stable set of beliefs, feelings and behaviours, in this case, towards refugees, i.e., people who migrate forcibly, motivated through no fault of their own. Attitudes are sensitive to change and different contexts, being different even in regions within the same country [18].

Studies about attitudes towards refugees have been differentiated from others exclusively focused on the attitudes of migrant people. These attitudes have been explained on the basis of different variables. In the case of attitudes towards refugees, there is a major influence of political and ideological factors on the existence of xenophobia and hate, while for refugees it is economic reasons that carry the most weight $[19,20]$. Concretely, these attitudes have been related to ethnic and national identity, social cohesion and national security, while concerns about jobs and revenues have a greater influence in the attitude towards immigrants [21].

\subsection{Inclusive European Citizenship}

Positive attitudes for the reception and integration of refugees, along with the appreciation and critical assessment of policies on the part of European institutions favourable to welcoming refugees, converge at the notion of democratic and inclusive European citizenship [22]. De Lucas [23] defined inclusive European citizenship as going beyond the limits of the nationalities of member states. Traditionally, the concept of citizenship (a legal status which is granted to the members of a community who have the same rights and obligations) has been linked to the concept of the nation-state; consequently, this expansion of the concept of citizenship is incorporated into the recognition of the universal right to free circulation, and thus we have the extension of the legal status of citizen to all the migrant people inhabitant in Europe, moving towards a citizenship model based on residency and the exercise of political rights [24]. This means, at the same time, the recognition of the native identities of people who arrive in Europe, respect for cultural differences, and essentially, the expansion of freedom, social and political rights to immigrants.

\subsection{Research Questions}

France is a country with an older democracy system compared to Spain. Over the years, this country has hosted many immigrant people from its former colonies, as well as workers from the South of Europe. Spain has been receiving immigrants since the 1960s, which is the period when its migration trend started to change, being a country characterized by immigration since then. On this basis, the questions which guide this investigation are:

1. What are the attitudes of university students who will become teachers (in both countries), to inclusive European citizenship, the feeling of threat, the recognition of rights and emotional reactions towards refugees who are arriving in the European Union?

2. The attitudes of European inclusive citizens towards refugees. Is it associated with the feeling of threat? How is the recognition of rights and emotional reactions towards refugees associated with European inclusive citizens?

Getting to know the relationship between these factors can help to design strategies of university education to improve inclusive European citizenship, to design inclusive educative programmes, and thereby to contribute to the achievement of the Millennial Development Goals for quality education and sustainable development [25-27]. 


\section{Materials and Methods}

\subsection{Participants}

The participants were 851 university students, out of which 499 belonged to the University of Almería (Spain) and 352 to the Faculty of Education at the University of Montpellier (France). All participants, both Spanish and French, were selected because, in the near future, they will be teachers, and will influence the perception and beliefs that children and adolescents have about society, and the coexistence established within it of people with different ethnic-cultural origins. The study was performed using a non-probabilistic sample of convenience of teachers in training from two geographical areas characterized by immigration: Montpellier, due to its long history of migratory reception, and Almería, for its recent high immigration levels. Of the participants, 667 (78.42\%) were women, and 184 were (21.6\%) men. The average age of the Spanish participants was 22.24 years old, with a standard deviation of 3.90, with ages ranging from 18 to 50 years old. The average age of French participants was 23.46 years old, with a standard deviation of 3.99 , with ages ranging from 18 to 51 years old.

\subsection{Measures}

Along with personal and demographic information (age, gender, residence and level of education), information on three scales was collected, two selected from other studies carried out with refugees and immigrants, and a third, previous and independently developed, focused on the arrival, recognition, and welcoming of refugees, especially those from Syria, in the European Union.

Threat and Rights Scale. This scale is based on the Realistic and Symbolic Threat Scale created by Stephan, Ibarra, and Bachman [28] and retrofitted in other studies [29-31]. In our case, we have utilized 9 of the 12 principles that conform to it. The factorial analysis performed on the items of the scale presents 2 factors, which we have labelled a Threat Subscale, composed of six principles (ex: the reception of refugees is undermining Spanish culture), and a Rights Subscale that looks at three principles (ex: refugees have the same rights to help in situations of poverty as Spaniards). The response format is a Likert scale of five points, which range from 1 "totally disagree" to 5 "totally agree".

This scale was transculturally validated for the French version following a translation process by bilingual experts (Spanish-French), and the French version of the scale was translated back into Spanish by two bilingual people to verify that the meaning of each of the statements was maintained. The factorial analysis of the scale in French also informs on two factors, with the same items that had been obtained in the validation of the scale in Spain.

In both scales, all the negative principles are codified in an inverse manner and then joined with the positives, in such a way that high values on this scale determine less threat and more rights for the recently arrived. The total reliability of the scale was $\alpha=0.734$ in Spain and $\alpha=0.829$ in France. The Threat Subscale scored $\alpha=0.734$ in Spain and $\alpha=0.807$ in France. The Rights Subscale scored $\alpha=0.64$ in Spain and $\alpha=0.783$ in France.

Affective Reactions Scale. This scale is adapted from the Prejudicial Attitude Survey created by Stephan and Stephan [29] and the Emotions Scale denoted by Garcia et al. [32]. The original scale consists of 12 terms, 6 emotions (ex: Hatred), and 6 evaluations (ex: Admiration). We have modified the scale and have added a conclusion, so that there are 10 conclusions (Sympathy, Hatred, Admiration, Indifference, Confidence, Rejection, Acceptance, Affection, Superiority and Warmth). The responses were codified from 1 to 10 , in which the students were asked to indicate the intensity in response produced by thinking about and seeing a refugee person (specifically, the refugees that arrive in Spain and the European Union fleeing wars), 1 meaning "nothing" and 10 meaning "a lot". All of the words of negative value (ex: Hatred) are codified in an inverse manner, and then joined with the words of positive value (ex: Sympathy) in such a way that the highest values reflect less prejudicial feelings, thus, implying more acceptance and a larger positive affect. For our study, the scale was translated into French. The total scale had a reliability of $\alpha=0.837$ in Spain and $\alpha=0.869$ in France. 
Inclusive European Citizenry scale. This scale was elaborated by Spanish researchers and is centred in the perception of the European Union's role and in civic beliefs surrounding the arrival of refugees [33]. This scale is formed by ten items, 2 positive principles (ex: The arrival of refugee persons to the European Union is an opportunity to educate on peaceful coexistence) and 8 negative principles (ex: The refugee crisis could break the European Union). The response format is a Likert scale of 5 points that range from 1 meaning "totally disagree" to 5 points meaning "totally agree". The scale was translated into French and validated. Like in the other two scales, all the negative principles are codified in an inverse manner, and then joined with the positively formulated principles, so that the highest marks show greater reception and a positive vision towards refugees that arrive in the European Union. For this scale the reliability was $\alpha=0.731$ in Spain and $\alpha=0.74$ in France.

\subsection{Procedure}

The participants were invited to participate voluntarily, and were informed that the study would explore the attitudes towards refugee persons with guaranteed anonymity. Once informed consent was given, the participants proceeded to complete the questionnaire. The investigators assigned the questionnaires in classrooms with the professor of the course present. The investigators were at the disposal of the students to resolve any doubts that could appear when completing the questionnaire.

\subsection{Informed Consent and Ethical Considerations}

All procedures performed in our study were in accordance with the ethical standards of the University of Almería, the national research committee, and with the 1964 Helsinki Declaration and its later amendments or comparable ethical standards. An informed consent was obtained from all participants included in the study.

\subsection{Data Analysis}

The data follow a normal distribution, on the basis of the asymmetry and kurtosis that are below the values [34]. A descriptive analysis of the results of scales was carried out. Next, we performed a multivariate analysis, starting with an analysis of variance (ANOVA), considering as dependent variables the results of each of the applied scales (inclusive European citizenship, Threat, Rights, Affective reactions), and as factors the gender and the country (Spain, France). Finally, we carried out a correlational study and hierarchical regressions considering European inclusive citizenship as a dependent variable or criterion, and age, Threat, Rights and Affective reactions as predictor variables. The level of significance was set at $\alpha=0.05$. The calculations were made using the Statistical Package for Social Sciences software (SPSS for Windows 23.0).

\section{Results}

The scales of Threats, Rights, and Affective Reactions, and the survey of inclusive European citizenship, do not have quantitative cut-off points to decipher negative, neutral, and positive attitudes and prejudices. Thus, descriptive statistics are calculated (Mean and Standard Deviation) for each one of the three scales (see Table 1).

The highest average score on a scale from 1 to 5 is found in the scale of Rights, 3.87 in the Spanish group and 3.91 in the French group, with no significant differences among the two compared nationalities $(t=849 ; p=0.485)$. The rest of the scores are approximately 3.11 (threat scale for Spanish) and 3.83 (threat scale for French), in this case significant differences were identified $(t=-13,28$; $p=0.000)$. The Inclusive European Citizenship variable showed significant differences between them $(\mathrm{t}=-5,051 ; p=0.000)$.

The range of means obtained across the three scales by Spanish and French groups (from 3.11 to 3.91) can be interpreted as a certain indifference or a minimal positive attitude of the participants toward refugees. On the other hand, for the scales from 1 to 10, the scales of Affective Reactions have an average below 5, both in French (7.14) and in Spanish (6.95) groups, with no significant differences 
found between them $(t=-1,814, p=0.07)$. These measures show a less neutral and more positive attitude towards refugees.

Table 1. Descriptive statistics for study variables and the correlation among them.

\begin{tabular}{|c|c|c|c|c|c|c|c|c|}
\hline & \multicolumn{4}{|c|}{ Spanish } & \multicolumn{4}{|c|}{ French } \\
\hline & $\begin{array}{l}\text { Inclusive European } \\
\text { Citizenship }\end{array}$ & Threats & Rights & $\begin{array}{l}\text { Affective } \\
\text { Reactions }\end{array}$ & $\begin{array}{c}\text { Inclusive European } \\
\text { Citizenship }\end{array}$ & Threats & Rights & $\begin{array}{l}\text { Affective } \\
\text { Reactions }\end{array}$ \\
\hline $\mathrm{M}$ & 3.25 & 3.11 & 3.87 & 6.95 & 3.47 & 3.83 & 3.91 & 7.14 \\
\hline$\alpha$ & 0.731 & 0.734 & 0.64 & 0.837 & 0.74 & 0.807 & 0.783 & 0.869 \\
\hline $\begin{array}{l}\text { Inclusive European } \\
\text { Citizenship }\end{array}$ & 1 & & & & 1 & & & \\
\hline Affective Reactions & $0.554 * *$ & $0.679 * *$ & 0.0433 ** & 1 & $0.469^{* *}$ & $0.502 * *$ & $0.343 * *$ & 1 \\
\hline
\end{tabular}

Note. ${ }^{* *} p=0.000$. M. Mean SD. Standard Deviation $\alpha$. Cronbach's alpha.

\subsection{Analysis of Attitudes toward Refugees by Gender}

An analysis of variance (ANOVA) was carried out for each one of the applied scales. The results obtained in the scales are formed by dependent variables while "gender" and "country" variables are considered independent variables. Bonferroni correction was used for the adjustment of multiple comparisons. As they are dichotomous independent variables, multiple post hoc comparisons were not made for the obtained means. The effect size was obtained through $\eta^{2}$. The results of these analyses are shown in Tables 2 and 3.

Table 2. Means and standard deviations of the study variables by gender and country.

\begin{tabular}{|c|c|c|c|c|c|}
\hline \multirow[b]{2}{*}{ Gender } & \multirow[b]{2}{*}{ Country } & \multirow{2}{*}{$\begin{array}{c}\text { Inclusive European Citizenship } \\
\text { M (SD) }\end{array}$} & \multirow{2}{*}{$\begin{array}{l}\text { Threat } \\
\text { M (SD) }\end{array}$} & \multirow{2}{*}{$\begin{array}{l}\text { Rights } \\
\text { M(SD) }\end{array}$} & \multirow{2}{*}{$\begin{array}{c}\text { Affective Reactions } \\
\mathrm{M}(\mathrm{SD})\end{array}$} \\
\hline & & & & & \\
\hline \multirow{2}{*}{ Male } & Spain & $3.24(0.63)$ & $3.20(0.74)$ & $3.79(0.81)$ & $6.96(1.41)$ \\
\hline & France & $3.25(0.80)$ & $3.45(0.97)$ & $3.47(1.3)$ & $6.72(1.71)$ \\
\hline \multirow{2}{*}{ Female } & Spain & $3.26(0.61)$ & $3.08(0.74)$ & $3.89(0.85)$ & $6.95(1.34)$ \\
\hline & France & $3.52(0.59)$ & $3.9(0.75)$ & $4(0.87)$ & $7.22(1.49)$ \\
\hline
\end{tabular}

Table 3. Inter-subject effects.

\begin{tabular}{ccccccccccccc}
\hline & \multicolumn{1}{c}{ Inclusive European Citizenship } & \multicolumn{3}{c}{ Threat } & \multicolumn{3}{c}{ Rights } & \multicolumn{3}{c}{ Affective Reactions } \\
\hline & $\mathbf{F}$ & $\boldsymbol{p}$ & $\boldsymbol{\eta}^{\mathbf{2}}$ & $\mathbf{F}$ & $\boldsymbol{p}$ & $\boldsymbol{\eta}^{\mathbf{2}}$ & $\mathbf{F}$ & $\boldsymbol{p}$ & $\boldsymbol{\eta}^{\mathbf{2}}$ & $\mathbf{F}$ & $\boldsymbol{p}$ & $\boldsymbol{\eta}^{\mathbf{2}}$ \\
\hline Gender & 6,69 & 0.010 & 0.007 & 5.94 & 0.015 & 0.005 & 16.14 & 0.000 & 0.018 & 3.79 & 0.05 & 0.004 \\
Country & 5.91 & 0.015 & 0.006 & 62.39 & 0.000 & 0.059 & 1.95 & 0.16 & 0.002 & 0.018 & 0.89 & 0.000 \\
Gen*Cou & 5.28 & 0.022 & 0.006 & 17.64 & 0.000 & 0.016 & 7.56 & 0.006 & 0.009 & 3.95 & 0.047 & 0.004 \\
\hline
\end{tabular}

From a gender perspective, significant differences among males and females were observed in the four scales applied. The women obtained the best scores in the scales of inclusive European citizenship and rights, and French women in the scale of Threat and Affective Reactions. If we consider the country, we observe significant differences between the French and Spaniards in the scales of inclusive European Citizenship and Threat, the French being those that obtain higher scores. In the interaction between sex and country, as expected, significant differences were observed in the four scales applied. The scores of the women are higher than that of the men except in the perceived Threat subscale, where Spanish women obtain the lowest score $(\mathrm{M}=3.08)$, that is to say, they are those that feel more threat, or are the most indifferent, with the arrival of refugees to the European Union. The French women are those who feel less threat, even so, they maintain a certain indifference towards the refugees $(M=3.9)$. They consider the refugees to have more rights $(\mathrm{M}=4)$ and they express more positive affective reactions $(\mathrm{M}=7.22)$. 


\subsection{Predictive Study: Correlations between Attitudes toward Refugees and Inclusive European Citizenship}

Positive correlations are observed in almost all of the scales. In addition, the French students obtain higher correlations than Spaniards at all scales. The highest correlation is found between the subscale of Threat and Affective Reactions scale (.679), followed by the Inclusive European Citizenship scale with the Threat subscale (.655) and the Affective Reactions scale (.554)

In order to know how the criterion variable of Inclusive European Citizenship behaves, considering the obtained score in this questionnaire, in function with the independent variables or the "Subscales of Rights, Affective Reactions and Threats" predictors, a hierarchical regression was carried out (see Table 4).

Table 4. Summary of the hierarchical regression for inclusive European citizenship for Spanish and French groups.

\begin{tabular}{|c|c|c|c|c|c|c|c|}
\hline & \multicolumn{3}{|c|}{ Spanish } & & \multicolumn{3}{|c|}{ French } \\
\hline & $\mathbf{R}^{2}$ & $\beta$ & $p$ & & $\mathbf{R}^{2}$ & $\beta$ & $p$ \\
\hline Model 1 & 0.341 & & & Model 1 & 0.429 & & \\
\hline Threats & & 0.584 & 0.000 & Threats & & 0.655 & 0.000 \\
\hline Model 2 & 0.382 & & & Model 2 & 0.451 & & \\
\hline Threats & & 0.465 & 0.000 & Threats & & 0.517 & 0.000 \\
\hline \multirow[t]{5}{*}{ Affective Reactions } & & 0.236 & 0.000 & Affective Reactions & & 0.203 & 0.000 \\
\hline & & & & Model 3 & 0.463 & & \\
\hline & & & & Threats & & 0.480 & 0.000 \\
\hline & & & & Affective reactions & & 0.173 & 0.000 \\
\hline & & & & Rights & & 0.127 & 0.005 \\
\hline
\end{tabular}

Through successive steps, 2 models are recognized for Spaniards. The system rejects a third and fourth model in which the age and score of the Rights scale are introduced as regressors, since they would be regressors that do not contribute anything substantive. The first regression model explains $34.1 \%$ of the variance that the variance analysis test shows, where the value of $\mathrm{F}$ is 256.9 , whose associated probability is 0.000 , which indicates a real effect of the variable Threat on the criterion variable "Inclusive European Citizenship", which also gathers citizen beliefs before the arrival of refugees. The second model explains $38.2 \%$ of the variance. The value of $\mathrm{F}$ is 153.4 , and the associated probability is 0.000 , which shows a real effect of the variables Threat and Affective Reactions on the criterion variable, although the most significant effect is shown for the predictor Threat.

The correlation we have seen between the two predictors could suggest a multicollinearity problem. The variance inflation factor (VIF) was less than 1.5, and the condition index was less than 12, so multicollinearity is ruled out.

For the French participants, 3 models are recognized. The system rejects the fourth model in which age is introduced as a regressor. The first model explains $42.9 \%$ of the variance, where the value of $F$ is 261.8 , and the associated probability is 0.000 . This indicates a real effect of the Threats variable on the "Inclusive European Citizenship" variable, which also recognizes civic beliefs before the arrival of refugees. The second model explains $45.1 \%$ of the variance, the associated value of $\mathrm{F}$ is 142.9 , and the associated probability is 0.000 , which shows the real effect of the variables Threat and Affective Reactions. The third model explains $46.3 \%$ of the variance, the associated value of $F$ being 99.8, and the probability 0.000 . The three models show a real effect of the variables Threat, Affective Reactions and Rights, although the Threat Predictor is the one that shows the most significant effect. In both models, for Spaniards and French, the prejudiced attitude of perceived Threat is the one that has the greatest specific weight.

What explains these models is that, in our future teachers, an attitude of acceptance and support toward refugees, especially toward Syrian refugees that arrive to the European Union, depends upon any perceived threat. Positive reactions toward these unprotected people who seek refuge in the European Union carry less weight. In order to find out how attitudes of Threats, Rights and Affective Reactions predict the ability to welcome and integrate people of other ethnic groups and cultures that 
request asylum in the European Union, hierarchical regressions were carried out according to sex and nationality.

Table 5 shows that for French men, the perception of Threat is the one that best predicts an attitude of reception and inclusion in Europe for people fleeing from wars $(\beta=0.728)$. Although the feeling of Threat is also important for Spaniards when predicting the level of reception of others, Affective reactions and Rights can also predict a positive welcome, again with the feeling of threat being the factor that carries the greatest specific weight.

Table 5. Summary of the hierarchical regression for inclusive European citizenship in Spanish and French males.

\begin{tabular}{cccccccc}
\hline & \multicolumn{3}{c}{ Spanish } & & \multicolumn{3}{c}{ French } \\
\cline { 2 - 7 } & $\mathbf{R}^{\mathbf{2}}$ & $\boldsymbol{\beta}$ & $\boldsymbol{p}$ & & $\mathbf{R}^{\mathbf{2}}$ & $\boldsymbol{\beta}$ & $\boldsymbol{p}$ \\
\hline Model 1 & 0.372 & & & Model 1 & 0.530 & & \\
Threats & & 0.610 & 0.000 & Threats & & 0.728 & 0.000 \\
\hline Model 2 & 0.403 & & & & & \\
Threats & & 0.485 & 0.000 & & & \\
Affective Reactions & & 0.215 & 0.013 & & & \\
\hline Model 3 & 0.423 & & & & & \\
Threats & & 0.469 & 0.000 & & & \\
Affective reactions & & 0.176 & 0.043 & & & \\
Rights & & 0.153 & 0.038 & & & \\
\hline
\end{tabular}

Table 6 indicates that for Spanish and French women, the perceived Threat is the factor that predicts the reception of refugees in the European Union the most. For both countries, Affective reaction appears as a predictor of the reception of people fleeing from wars, although this predictor does not have the specific weight that the perceived threat has. The Rights variable predictor is also observed in French women, although with a low weight $(\beta=0.101)$.

Table 6. Summary of the hierarchical regression for inclusive European citizenship in Spanish and French females.

\begin{tabular}{|c|c|c|c|c|c|c|c|}
\hline & \multicolumn{3}{|c|}{ Spanish } & & \multicolumn{3}{|c|}{ French } \\
\hline & $\mathbf{R}^{2}$ & $\beta$ & $p$ & & $\mathbf{R}^{2}$ & $\beta$ & $p$ \\
\hline \multirow{2}{*}{$\begin{array}{l}\text { Model } 1 \\
\text { Threats }\end{array}$} & 0.334 & & & Model 1 & 0.379 & & \\
\hline & & 0.578 & 0.000 & Threats & & 0.616 & 0.000 \\
\hline \multirow{7}{*}{$\begin{array}{c}\text { Model } 2 \\
\text { Threats } \\
\text { Affective } \\
\text { Reactions }\end{array}$} & 0.378 & & & Model 2 & 0.413 & & \\
\hline & & 0.464 & 0.000 & Threats & & 0.474 & 0.000 \\
\hline & & 0.238 & 0.000 & $\begin{array}{l}\text { Affective } \\
\text { Reactions }\end{array}$ & & 0.232 & 0.000 \\
\hline & & & & Model 3 & 0.421 & & \\
\hline & & & & Threats & & 0.448 & 0.000 \\
\hline & & & & $\begin{array}{l}\text { Affective } \\
\text { reactions }\end{array}$ & & 0.212 & 0.000 \\
\hline & & & & Rights & & 0.101 & 0.04 \\
\hline
\end{tabular}

\section{Discussion}

This study analyses the attitudes of Spanish and French future teachers towards refugees and levels of inclusive European citizenship, attending to their assessment about the European Union and their recognition of refugees' rights. Also, the study explores the relationships between attitudes towards refugees and the creation of an open European citizenship, which regards migrants as having the status of full members. The identification of inequalities in the educative system and of teachers' 
predispositions towards inclusion and welcoming is crucial to meeting the goals set out by the 2030 Agenda on Sustainable Development Goals [25]. Specifically, by 2030, goal 4.5 proposes to ensure equal access to all levels of education and vocational training for vulnerable people, and goal 4.7 is to ensure that all learners acquire the knowledge and skills needed to promote sustainable development, including promotion of a culture of peace and non-violence, global citizenship and appreciation of cultural diversity.

The first finding about attitudes towards refugees is, generally, a modest indifference towards the situation of refugees from future teachers. This indifference is appreciated in the tendency for central scores in the threats and rights scale (close to 3 ) and a low deviation in mean values, being more noticeable in the Spanish sample. This measurement of central and positive punctuations contradicts reports of growing feelings of threat and the increasing belief that competition for resources is high throughout the population [35,36]. Future teachers, university students, do not show negative attitudes. In fact, selflessness and misinformation towards refugees among young people is a phenomenon which has been registered in other European studies [37]. Low levels of threat from the Spanish sample, information taken from Cala, Soriano \& López-Martínez [33], coincides with a lower reception of immigrants compared to the levels predicted since the beginning of the period known as the refugee crisis in Europe and a low generalized concern in the Spanish population towards migration as a social and political priority, as established in CIS [38] and Euro barometer [12].

The second relevant question is the fact that the results show more positive attitudes towards refugees in the French sample than the Spanish, contradicting the European statistics results which put Spain ahead in terms of openness to hosting refugees [12-14]. Concretely, significant differences are appreciated for perceived threat, being remarkably low in French students. This better predisposition in future French teachers can correspond to different reasons. Firstly, it responds to a worsening of attitudes in the Spanish population. Since 2017, there has been a change of politics, leaning towards right-wing parties with xenophobic views, who promote a narrative of 'invasion', which means the entry into power for many ultra-right parties to govern some regions in Spain for the very first time [39]. This type of speech might be associated with a transformation in attitudes towards refugees that has not been reflected in other European surveys. Another explanation lies in the nature of the sample. European studies use samples which represent the social whole, not only students from Education faculties of small and rural cities.

University student samples might be associated with a more positive vision influenced by the role of public universities in the construction of inclusive citizenship and the formation of welcoming attitudes. Even though France has historically been of the most representative examples of European democracy, French universities have been some of the most important institutions which transmit French values and the French republicanism model, and have been strong defenders of human rights [40]. Similarly, the migrant trajectory in France with a bigger cultural contact, according to the theory of contact, can positively influence the sensitivity to inclusiveness. Also, the politicization of integration is another factor to take into consideration.

There is an inclusive European feeling among future teachers from both groups, especially striking in the French ones. Facing pessimistic speeches about crisis in Europe, there is recognition by participants of the role of European institutions, and a positive reaction to the arrival of migrants, giving them the same rights as themselves. The most punctuated items are the ones about building a more inclusive and collective Europe, perceiving migrants' arrival as an opportunity to educate in tolerance and coexistence. This democratic point of view from the European Union (EU) has its roots in different foundation myths [41]. The first one, in the case of Spanish groups, is the consolidation of a democratic Spain by gaining membership of the EU back in 1986. Another one is the implementation of educative programmes of identity reinforcement and European participation through Erasmus programs [42].

From a gender perspective, there are remarkable differences in the scale of citizenship and attitudes towards citizens. Women show more sensitivity and empathy to migrants, showing more intense and positive emotional reactions than men. Also, traditional gender roles have resulted in a higher 
intercultural sensitivity and solidarity in women $[43,44]$. Gender role distribution concedes to women the care and maintenance of social bonds, including the responsibility of making people safe and protected, helping their emotional and communicative skills. According to Tompkins et al. [41], men are more concerned about success, rather than getting to know other people. Also, they focused on cultivating social skills, travelling etc., attitudes which lead to less sensitive and equal positions.

The fifth idea arising from this study is the predictive capacity of the level of inclusive European citizenship upon attitudes towards refugees, which means that the more positive the arrival of migrants appears, the more accepted it will be, and so the greater the concession of rights upon them. The feeling of threat is the dimension which is the most predicted by inclusive European citizenship, followed by positive emotional reactions [45]. Similarly, Stark, Mäs \& Flache [46] determine that the level of felt threat is related to factors like the existence of a multicultural ideology or the development of integration policies. According to Hermanni \& Neumann [47], the feeling of threat is the most important factor which explains the social rejection of refugees over cultural differences (typically arising from racism). According to Salmela \& von Scheve [48], contemporary capitalist societies are highly influenced by the feelings of fear and threat, which are the most widespread emotions, since capitalism is an individualist model which categorizes people based on success or failure in their lives. Unemployment and migration are assumed to originate from that logic, going from a feeling of threat to hate against enemies. These feelings are capitalized by right-wing parties. In this investigation, the feeling of threat related to refugees is the only predictive factor of an inclusive European citizenship in French men, with less threat predicting more citizenship. Spanish women are also influenced by emotional reactions about inclusive citizenship. Another emotional mechanism of xenophobic parties consists of empowering an emotional distancing of refugees [45]. Paradoxically, a positive attitude towards public and social rights for refugees (the right to access health care and education) has a low explanatory character in Spanish men and French women. This can be explained as a result of the naturalization of social rights, which are currently offered to migrant people in both countries.

\section{Limitations of the Study}

The results revealed throughout this document should be interpreted cautiously for various reasons. The sample of participants corresponds to a group of university students in the last years of their educational careers, so they are not results that are generalizable to the general population.

Also, the locations of our samples must be taken into account to contextualize the data. Almería and Montpellier are two small cities, located in southern Spain and France respectively, with about 200,000-250,000 inhabitants each, which means that they have a higher percentage of immigrant population than other regions of the country.

On the other hand, despite positive results towards inclusion, European studies continue to find an existing structural racism which can affect the real integration of refugees. As Pareja and López [49] establish, an appropriate perception and assessment of reception, or an absence of abstract discrimination, is not necessarily associated with adequate integration. They stress that, although future teachers give the same value to all cultures, their positions differ when it comes to clarifying the weight that the majority culture should carry in future policy, or the situation of social inequality experienced by members of cultures other than the native culture. Thus, an egalitarian assessment does not necessarily imply an egalitarian functional participation in the organization of social life.

\section{Conclusions}

The study makes a contribution to the field of global migration and intercultural citizenship from a sociocultural perspective, according to a sustainable development model which guarantees an inclusive coexistence and the full development of all human beings [25,27]. These results strongly support new European teachers' consciousness. This investigation offers two main ideas: Firstly, that generations of European teachers do not manifest any negative stereotypes or discourses of fear, and secondly, that the level of inclusive European citizenship depends on the perceived threat. 
Among the socioeducative implications of this investigation, one that is remarkable is the importance of working with fear and perceived threat towards refugees in order to make progress towards a better reception. Schools should be places for reflection, resistance and opposition to the lies, stereotypes and false rumours generated by populist right-wing parties in Europe. Similarly, the position of women towards the reception of migrants is particularly relevant. Deeper investigation is needed into the gender mechanisms that affect inclusive sensitivity, for the purpose of learning about new educational strategies.

Finally, in the current socioeconomic and political context, it is necessary to note the risk of a worsening in attitudes towards refugees. In our societies, attitudes and perceptions of intercultural and inclusive European citizenship are particularly sensitive to changes, which can be quickly modified in the future. Accordingly, it is essential to bring forward new training activities for teachers, and curricular changes that avoid any exclusionary attitudes in our schools [6].

Author Contributions: Conceptualization, E.S. and V.C.; Methodology, E.S.; Software, E.S.; Validation, E.S.; Formal Analysis, E.S.; Investigation, E.S and V.C.; Resources, V.C.; Data Curation, E.S. and V.C.; Writing-Original Draft Preparation, V.C.; Writing-Review \& Editing, V.C.; Visualization, E.S and V.C.; Supervision, E.S.; Project Administration, E.S.

Funding: This research received no external funding.

Conflicts of Interest: The authors declare no conflict of interest.

\section{References}

1. UNHCR. Global Trends: Forced Displacement in 2017; UNHCR: Geneva, Switzerland, 2018.

2. World Bank. Forcibly Displaced: Toward a Development Approach Supporting Refugees, the Internally Displaced, and Their Hosts; World Bank: Washington, DC, USA, 2017; Available online: https://openknowledge.worldbank. org/handle/10986/25016 (accessed on 15 April 2019).

3. UNHCR. Missing Out: Refugee Education in Crisis. Retrieved; UNHCR: Geneva, Switzerland, 2016; Available online: http://www.unhcr.org/missingout (accessed on 25 March 2019).

4. Wrench, A.; Soong, H.; Paige, K.; Garrett, R. Building spaces of hope with refugee and migrant-background students. Int. J. Incl. Educ. 2018, 22, 1197-1212. [CrossRef]

5. Dryden-Peterson, S. Refugee education in countries of first asylum: Breaking open the black box of pre-resettlement experiences. Theory Res. Educ. 2016, 14, 131-148. [CrossRef]

6. Banks, J.A.; Suárez-Orozco, M.; Ben-Peretz, M. (Eds.) Global Migration, Diversity, and Civic Education: Improving Policy and Practice; Teachers College Press: New York, NY, USA, 2016.

7. Sharkey, J. The promising potential role of intercultural citizenship in preparing mainstream teachers for im/migrant populations. Lang. Teach. Res. 2018, 22, 570-589. [CrossRef]

8. Li, G. Divergent paths, same destiny: A Bourdieusian perspective on refugee families' negotiation of urban school transition in the US. Eur. J. Educ. 2018, 53, 469-480. [CrossRef]

9. McWilliams, J.A.; Bonet, S.W. Continuums of precarity: Refugee youth transitions in American high schools. Int. J. Lifelong Educ. 2016, 35, 153-170. [CrossRef]

10. Yitmen, S.; Verkuyten, M. Positive and negative behavioural intentions towards refugees in Turkey: The roles of national identification, threat, and humanitarian concern. J. Community Appl. Soc. Psychol. 2018, 28, 230-243. [CrossRef]

11. Tarman, B.; Gürel, D. Awareness of social studies teacher candidates on refugees in Turkey. J. Soc. Stud. Res. 2017, 41, 183-193. [CrossRef]

12. Eurobarometer. Available online: http://ec.europa.eu/commfrontoffice/publicopinion/archives/eb_special_ 439_420_en.html (accessed on 30 March 2019).

13. Global Attitudes Survey. Available online: https://www.pewglobal.org/ (accessed on 20 April 2019).

14. European Social Survey. Available online: https://www.europeansocialsurvey.org/about/ (accessed on 10 April 2019).

15. Chabal, E. From the banlieue to the burkini: The many lives of French republicanism. Mod. Contemp. Fr. 2016, 25, 68-74. [CrossRef] 
16. Spina, E.L. Controlling Immigrant Integration in the Euro-Mediterranean Region: A Compelling Turnaround in Times of Economic Crisis. Revista Crítica de Ciências Sociais 2017, 114, 5-26. [CrossRef]

17. Retortillo, Á.; Ovejero, A.; Cruz, F.; Arias, B.; Lucas, S. Inmigración y modelos de integración: Entre la asimilación y el multiculturalismo. Revista Universitaria de Ciencias del Trabajo 2006, 7, 123-139.

18. Crawley, H.; Drinkwater, S.; Kauser, R. Regional Variations in Attitudes Towards Refugees: Evidence from Great Britain; Institute for the Study of Labor (IZA): Bonn, Germany, 2013; (ISA Discussion Paper Series; 7647).

19. .Getmansky, A.; Sinmazdemir, T.; Zeitzoff, T. Refugees, xenophobia, and domestic conflict: Evidence from a survey experiment in Turkey. J. Peace Res. 2018, 55, 491-507. [CrossRef]

20. Steele, L.G.; Abdelaaty, L. Ethnic diversity and attitudes towards refugees. J. Ethn. Migr. Stud. 2018, 1, 1-24. [CrossRef]

21. Semyonov, M.; Raijman, R.; Gorodzeisky, A. Foreigners' impact on European societies: Public views and perceptions in a cross-national comparative perspective. Int. J. Comp. Sociol. 2018, 49, 5-29. [CrossRef]

22. Gualda, E. Inmigración, ciudadanía y gestión de la diversidad; Universidad Internacional de Andalucía: Sevilla, Spain, 2011.

23. De Lucas, J. Hacia una ciudadanía europea inclusiva. Su extensión a los inmigrantes. Revista CIDOB d'Afers Internacionals 2001, 53, 63-75.

24. De Lucas, J. La ciudadanía basada en la residencia y el ejercicio de los derechos políticos de los inmigrantes. Cuadernos Electrónicos de Filosofía del Derecho 2006, 13, 1-51.

25. United Nations. Transforming Our World: The 2030 Agenda for Sustainable Development; United Nations: Geneva, Switzerland, 2015.

26. Ainscow, M. Developing inclusive education systems: What are the levers for change? J. Educ. Chang. 2015, 6, 109-124. [CrossRef]

27. Santos Rego, M.A. Sostenibilidad y educación intercultural: El cambio de perspectiva. Bordón Revista de Pedagogía 2011, 63, 123-135.

28. Stephan, W.G.; Ybarra, O.; Bachman, G. Prejudice Toward Immigrants. J. Appl. Soc. Psychol. 1999, 29, 2221-2237. [CrossRef]

29. Stephan, W.G.; Stephan, C. Cognition and affect in stereotyping: Parallel interactive networks. In Affect, Cognition and Stereotyping: Interactive Processes in Group Perception; Mackie, D.M., Hamilton, D.L., Eds.; Academic Press: Orlando, FL, USA, 1993; pp. 111-136. [CrossRef]

30. Murray, K.E.; Marx, D.M. Attitudes toward unauthorized immigrants, authorized immigrants, and refugees. Cult. Divers. Ethn. Minor. Psychol. 2013, 19, 332. [CrossRef]

31. Schweitzer, R.; Perkoulidis, S.A.; Krome, S.; Ludlow, C.N. Attitudes towards Refugees: The Dark Side of Prejudice in Australia. Aust. J. Psychol. 2005, 57, 170-179. [CrossRef]

32. García, M.C.; Navas, M.S.; Cuadrado, I.; Molero, F. Inmigración y prejuicio: Actitudes de una muestra de adolescentes almerienses. Acción Psicológica 2003, 2, 137-147.

33. Cala, V.C.; Soriano-Ayala, E.; López-Martínez Manuel, J. Attitudes toward refugees and inclusive European citizenship. Analysis for an intercultural educational proposal with teachers in training. Relieve-Revista Electrónica de Investigación y Evaluación Educativa 2018, 24, 1-13.

34. Bollen, K.A.; Long, J.S. Testing Structural Equation Models; Sage: Newbury Park, CA, USA, 1993.

35. Plener, P.L.; Groschwitz, R.C.; Brähler, E.; Sukale, T.; Fegert, J.M. Unaccompanied refugee minors in Germany: Attitudes of the general population towards a vulnerable group. Eur. Child Adolesc. Psychiatry 2017, 26, 733-742. [CrossRef] [PubMed]

36. Dixon, T.; Hawkins, S.; Heijbroek, L.; Juan-Torres, M.; Demoures, F. Attitudes towards National Identity, Immigration and Refugees in Italy; More in Common Ltd.: London, UK, 2018.

37. Padilla, B.; Goldberg, A. Real and symbolic dimensions of the "refugee crisis" in Europe: A critical analysis from Portugal. REMHU: Revista Interdisciplinar da Mobilidade Humana 2017, 25, 11-27.

38. CIS. Available online: http://www.cis.es/cis/opencms/EN/2_bancodatos/DatosAbiertos.html (accessed on 14 April 2019).

39. Franquesa, J. The vanishing exception: Republican and reactionary specters of populism in rural Spain. J. Peasant Stud. 2019, 1, 1-24. [CrossRef]

40. Roebroeck, E.; Guimond, S. Schooling, citizen-making, and anti-immigrant prejudice in France. J. Soc. Political Psychol. 2015, 3, 20-42. [CrossRef] 
41. Cerutti, F.; Lucarelli, S. (Eds.) The Search for a European Identity: Values, Policies and Legitimacy of the European Union; Routledge: London, UK, 2008.

42. Cadavieco, J.F.; Pascual, Á. Estudio de las acciones Erasmus en Educación Superior. Magister 2013, $25,74-82$. [CrossRef]

43. Christov-Moore, L.; Simpson, E.A.; Coudé, G.; Grigaityte, K.; Iacoboni, M.; Ferrari, P.F. Empathy: Gender effects in brain and behavior. Neurosci. Biobehav. Rev. 2014, 46, 604-627. [CrossRef] [PubMed]

44. Tompkins, A.; Cook, T.; Miller, E.; LePeau, L.A. Gender influences on students' study abroad participation and intercultural competence. J. Stud. Aff. Res. Pract. 2017, 54, 204-216. [CrossRef]

45. De Oliveira, D.R.; Techio, E.M.; Páez, D.; Herranz, K. Factores predictores de las actitudes ante la inmigración. Revista de Psicología Social 2005, 20, 19-37. [CrossRef]

46. Stark, T.H.; Mäs, M.; Flache, A. Liking and disliking minority-group classmates: Explaining the mixed findings for the influence of ethnic classroom composition on interethnic attitudes. Soc. Sci. Res. 2015, 50, 164-176. [CrossRef] [PubMed]

47. Hermanni, H.; Neumann, R. 'Refugees welcome?' The interplay between perceived threats and general concerns on the acceptance of refugees-A factorial survey approach in Germany. J. Ethn. Migr. Stud. 2019, 45, 349-374. [CrossRef]

48. Salmela, M.; von Scheve, C. Emotional roots of right-wing political populism. Soc. Sci. Inf. 2017, 56, 567-595. [CrossRef]

49. Pareja, E.F.H.; López, M. Interculturality and teacher education: A study from pre-service teachers' perspective. Aust. J. Teach. Educ. 2018, 43, 74. [CrossRef]

(C) 2019 by the authors. Licensee MDPI, Basel, Switzerland. This article is an open access article distributed under the terms and conditions of the Creative Commons Attribution (CC BY) license (http://creativecommons.org/licenses/by/4.0/). 